\title{
Effects of human full-length amelogenin on the proliferation of human osteoblasts.
}

\author{
Ryo Kunimatsu*, Yuki Yoshimi, Tetsuya Awada, Kotaro Tanimoto \\ Department of Orthodontics and Craniofacial Developmental Biology, Hiroshima University Graduate School of \\ Biomedical Sciences, 1-2-3 Kasumi, Minami-ku, Hiroshima 734-8553, Japan
}

\begin{abstract}
Objective: Amelogenins are known as a major constituent of the enamel matrix secreted by ameloblasts and play an important role in enamel formation. Amelogenin knockout mice exhibit enhanced osteoblast formation and resorption of tooth cementum. Recent studies have revealed that amelogenins also have cell signaling properties. However, the biological functions of amelogenin in osteoblasts remain unclear. In this study, we examined the effects of recombinant human full-length amelogenin (rh174) on the proliferation of cultured normal human osteoblasts (NHOst).

Methods: NHOst cells were cultured and treated with $100 \mathrm{ng} / \mathrm{ml}$ rh174. Cell proliferation was evaluated using MTS assay in a time-dependent manner. Expression of Lysosomal-associated membrane protein 1 (LAMP 1), a possible amelogenin receptor, in NHOst cells was analyzed. NHOst cells were cultured and treated with $100 \mathrm{ng} / \mathrm{ml} \mathrm{rh174}$ in the presence or absence of LAMP 1-blocking antibody. Cell proliferative activity was analyzed by BrdU assay. Phosphorylation of extracellular signal regulated kinases (ERK) $1 / 2$ was measured by ELISA and western blotting analysis.

Results: Proliferation of NHOst cells was enhanced significantly $(p<0.01)$ by treatment with rh174, and was inhibited significantly $(p<0.01)$ by addition of anti-LAMP 1-blocking antibody. In addition, the ratio of phosphorylated ERK1/2 to total ERK1/2 was significantly larger $(\mathbf{p}<0.01)$ with $r$ h174 treatment, and was reduced significantly by the addition of anti-LAMP 1-blocking antibody in NHOst cells.

Conclusion: These results confirmed that rh174 interacts with LAMP 1, and rh174/LAMP 1 interaction activates the ERK1/2 signaling pathway, enhancing the proliferation activity of NHOst cells.
\end{abstract}

Keywords: Osteoblasts, LAMP1, Osteoblast, Amelogenin.

Accepted on May 16, 2018

\section{Introduction}

Several attempts have been made to restore periodontal tissue loss induced by periodontitis. Enamel matrix derivative (EMDOGAIN) (Straumann Institute, Basel, Switzerland), which is extracted from developing porcine tooth germs, has been widely used to regenerate periodontal tissue [1]. The clinical use of EMDOGAIN is based on the observation that Hertwig's epithelial root sheath deposits an enamel-like matrix on the dentin surface of the developing root [2]. Clinical studies have shown that EMDOGAIN successfully promotes cementum and alveolar bone formation in periodontal tissue [2,3]. In addition, other clinical studies of EMDOGAIN treatment for intrabony periodontal defects have found that it leads to regeneration of the periodontal ligament, and markedly enhances clinical attachment and alveolar bone growth [4-6]. However, the mechanism of its effects has not been fully clarified, possibly because the exact nature of the inducer among the numerous proteins included in EMDOGAIN remains unclear.
Among the protein components of the enamel extracellular matrix, amelogenins account for approximately 90\% [7,8]. Amelogenins play a crucial role in the mineralization and structural organization of developing enamel [9]. In addition, recent studies have revealed tooth root resorption, as well as amelogenesis imperfecta, in amelogenin-deficient mice $[10,11]$.

Lysosome-associated membrane protein 1 (LAMP 1) is a transmembrane protein that is expressed in late endosomes and lysosomes, and is often used as a marker for these two organelles [12]. LAMP 1 immunoreactivity is also observed at the plasma membrane and in early endocytic compartments [13]. The presence of LAMP 1 on the plasma membrane suggests that LAMP 1 acts as a cell surface receptor that can be shuttled to the lysosome through endocytosis. Thus, LAMP 1 may be involved in endocytosis, pinocytosis or phagocytosis [12]. A previous study demonstrated that amelogenins interact with LAMP 1 [14]. It is thus assumed that amelogenins affect the metabolism of osteoblasts through a LAMP 1-mediated mechanism. 
The purpose of this study was to examine the effects of recombinant human full-length amelogenin (rh174) on proliferation and the contribution of amelogenin/LAMP 1 interaction in human osteoblasts.

\section{Materials and Methods}

\section{Synthesis of rh174}

A plasmid containing rh174 cDNA (GI: 6715562 in Genbank), including exons 2, 3, 5, 6 and 7 without the signal peptide and anti-human amelogenin antibody was provided by Drs. PK. DenBesten and W. Li of the Department of Orofacial Sciences, University of California at San Francisco. rh174 was synthesized and purified as described elsewhere[15,16].

\section{Cell cultures}

Normal human osteoblasts (NHOst) (CC-2538; Cambrex Bio Science Walkersville Inc., Walkersville, MD) were cultured in 100-mm dishes (Corning, New York, NY) with Clonetics Osteoblast basal medium (OBM) (CC-3208; Science Walkersville Inc) and osteoblast growth medium (OGM) (CC-4193; Science Walkersville Inc) containing ascorbic acid, fetal bovine serum (FBS), and gentamicin/amphotericin-B (CC-3207; Science Walkersville Inc) at $37^{\circ} \mathrm{C}$ in an atmosphere containing $5 \% \mathrm{CO}_{2}$. The culture medium was changed every other day until $80 \%$ confluence. Cultures were then detached with $0.025 \%$ Trypsin $/ 0.01 \%$ EDTA Solution (CC-5034; Science Walkersville Inc), and were transferred to other dishes. NHOst in the $2^{\text {nd }}$ to $4^{\text {th }}$ passages were used for subsequent experiments.

\section{Quantification of cell number by 3-(4, 5- dimethylthiazol-2-yl)-5-(3-car-boxymethoxyphenyl)-2- (4-sulfophenyl)-2H-tetrazolium (MTS) assay}

NHOst were seeded at a density of $4 \times 10^{4}$ cells/well in 6-well plates (Becton, Dickinson and Company, Franklin Lakes, NJ), and cultured with OGM (Science Walkersville Inc) containing $10 \%$ FBS (Science Walkersville Inc) in the presence or absence of $100 \mathrm{ng} / \mathrm{ml} \mathrm{rh} 174$ for 6 days. Medium was changed every other day. The degree of cell proliferation was examined by MTS assay using a CellTiter 96 AQueous One Solution Cell Proliferation Assay (Promega, Madison, MI) according to the manufacturer's instructions. Culture medium was removed, and cells were incubated with $200 \mu \mathrm{l}$ MTS reagent in $1000 \mu \mathrm{l}$ PBS for $2 \mathrm{~h}$ at $37^{\circ} \mathrm{C}$ in a humidified atmosphere with $5 \% \mathrm{CO}_{2}$. Absorbance at $490 \mathrm{~nm}$ was recorded using a microplate reader (Model 550; Bio-Rad, Hercules, CA). Cell number was quantified based on a calibration curve.

\section{Analysis of cell proliferation activity by BrdU immunoassay}

NHOst were seeded at a density of $1 \times 10^{3}$ cells/well in a 96well plate (FALCON, Franklin Lakes, NJ) and were cultured in OGM (Science Walkersville Inc) with $10 \%$ FBS until $60 \%$ confluence. These cells were treated with $100 \mathrm{ng} / \mathrm{ml} \mathrm{rh} 174$ in the presence or absence of $20 \mathrm{mg} / \mathrm{ml}$ rabbit anti-LAMP-1 antibody (ab24170; Abcam, Cambridge, MA) in serum-free OGM (Science Walkersville Inc). Cell proliferation activity was analyzed using a Cell Proliferation ELISA BrdU kit (Roche Diagnostics, Mannheim, Germany), in accordance with the manufacturer's instructions. Absorbance of samples was measured using a microplate reader (Model 550; Bio-Rad) at $450 \mathrm{~nm}$.

\section{Mitogen-activated protein kinases-extracellular signal regulated kinases (MAPK-ERK) activity}

NHOst were seeded at a density of $2 \times 10^{4}$ cells/well in a 96well plate (FALCON), and were cultured overnight in OGM (Science Walkersville Inc) containing 10\% FBS. Cells were then treated with $100 \mathrm{ng} / \mathrm{ml} \mathrm{rh174}$ in the presence or absence of $20 \mu \mathrm{g} / \mathrm{ml}$ rabbit anti-LAMP 1 polyclonal antibody (ab24170; Abcam) in serum-free OGM (Science Walkersville Inc). Rabbit polyclonal IgG antibody was used as the control. MAPK-ERK activity was measured at $30 \mathrm{~min}$ after treatment with rh174 using a Cellular Activation of Signaling ELISA (CASE) kit (SuperArray Bioscience, Frederick, MD). Expression of total ERK1/2 (tERK) and phosphorylated ERK1/2 (pERK) was examined in accordance with the manufacturer's protocol.

\section{Western blot analysis}

NHOst were lysed in 5X sodium dodecyl sulfate (SDS) sample buffer [125 mM Tris- $\mathrm{HCl}$ (pH 6.8), 4\% SDS, 10\% glycerol]. Protein concentration was determined using a bicinchoninic acid (BCA) Protein Assay Kit (Pierce, Rockford, IL). After addition of $10 \%$ 2-mercaptoethanol and $0.01 \%$ bromophenol blue, samples were boiled at $100^{\circ} \mathrm{C}$ for $3 \mathrm{~min}$. Ten micrograms of protein was resolved on 10\% SDS-polyacrylamide gels. Proteins were transferred to PVDF membranes using an iBlot gel transfer system (Invitrogen, Carlsbad, CA). Membranes were blocked with LI-COR blocking buffer (LI-COR, Cambridge, UK) at room temperature on a shaker for $1 \mathrm{~h}$. Primary antibodies were incubated with the membranes at room temperature for $2 \mathrm{~h}$. Anti-phospho ERK1/2 antibody (sc-7383; Santa Cruz Biotechnology, Santa Cruz, CA), antitotal ERK1/2 antibody (p44/42 MAPK (Erk1/2), \#4695; Cell Signaling Technology, Boston, MA) were used at 1:1000 dilution and anti- $\beta$-actin antibody (AC-15; Sigma-Aldrich, St. Louis, MO) was used at 1:5000 dilution. After primary antibody incubation, membranes were washed three times for 5 min each with $15 \mathrm{ml}$ of PBS and $0.1 \%$ Tween-20 before addition of secondary antibody conjugated to a fluorescent entity: IRDye $800 \mathrm{CW}$-conjugated goat anti-mouse IgG in LICOR blocking buffer (LI-COR). At the end of the incubation period, membranes were washed twice with $15 \mathrm{ml}$ of PBS and $0.1 \%$ Tween-20 and once with $15 \mathrm{ml}$ of PBS. Membranes were dried, visualized, and analyzed on the Odyssey ${ }^{\circledR}$ IR imaging system (LI-COR).

\section{Statistical analysis}

Experiments were repeated three times. Means and standard deviations were calculated from the data obtained, and 
differences were examined using Student's t-test or one-way analysis of variance (ANOVA), followed by Scheffe's multiple comparison test at significance levels of $\mathrm{p}<0.05$ and $\mathrm{p}<0.01$.

\section{Results}

\section{Effects of rh174 on proliferation of NHOst cells}

Proliferation of NHOst was enhanced significantly $(\mathrm{p}<0.01)$ by treatment with $100 \mathrm{ng} / \mathrm{ml} \mathrm{rh174}$, as compared to untreated controls, at 4 and 6 days after seeding (Figure 1).

\section{Effects of LAMP 1 blocking on enhancement of cell proliferation activity by rh174 in NHOst cells}

Proliferation activity of NHOst was enhanced significantly $(\mathrm{p}<0.01)$ by treatment with $100 \mathrm{ng} / \mathrm{ml} \mathrm{rh} 174$, as compared to untreated controls (Figure 2). Meanwhile, anti-LAMP 1 antibody significantly $(\mathrm{p}<0.01)$ inhibited the effects of rh174 on the proliferation NHOst cells, with proliferation activity reduced to a level similar to that in controls.

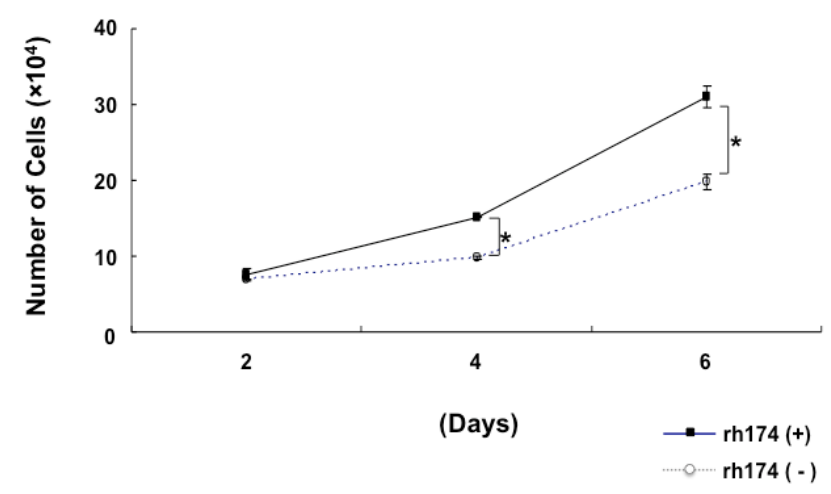

Figure 1. Effects of rh174 on proliferation of NHOst; NHOst were seeded at a density of $4 \times 10^{4}$ cells/well in 6-well plates, and were cultured with OGM containing 10\% FBS in the presence or absence of $100 \mathrm{ng} / \mathrm{ml} \mathrm{rh174}$. Cell proliferation was examined by MTS assay at 2, 4, and 6 days. ${ }^{*} P<0.01$, vs. control, $n=3$.

\section{Activation of ERK signaling pathway by interaction between rh174 and LAMP 1}

The ratio of pERK to tERK in NHOst became significantly larger $(\mathrm{p}<0.01)$ after treatment with $100 \mathrm{ng} / \mathrm{ml} \mathrm{rh} 174$, as compared to untreated controls. In addition, the increase in $\mathrm{pERK} / \mathrm{tERK}$ ratio by treatment with rh174 was reduced significantly $(\mathrm{p}<0.01)$ by addition of anti-LAMP 1 antibody (Figure 3).

\section{Activation of ERK signaling pathway by interaction between rh174 and LAMP 1 (western blotting)}

Western blot analysis revealed similar results of enhanced phosphorylated ERK1/2 signaling after addition of rh174. In addition, western blot analysis also revealed reduced phosphorylated ERK1/2 signaling after the blocking of LAMP 1 antibody. Lower bands show the abundance of total ERK and $\beta$-actin as a loading control (Figure 4).

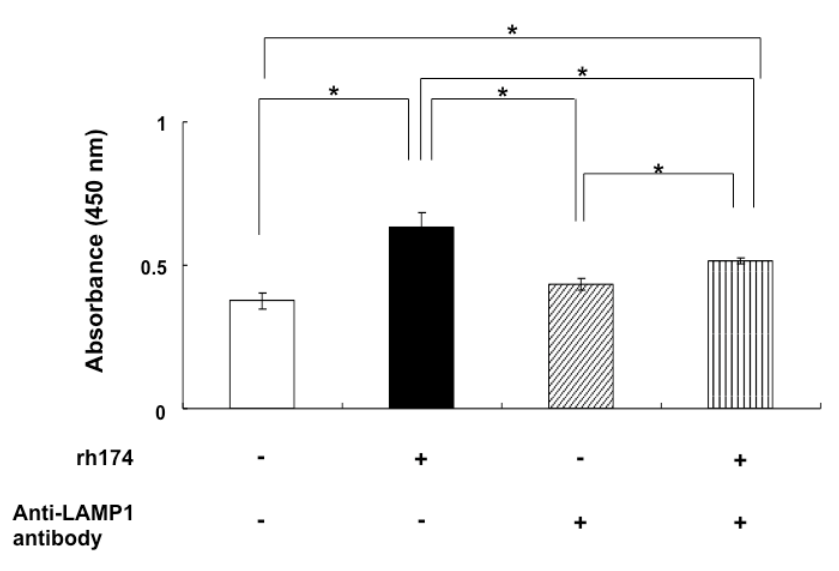

Figure 2. Effects of LAMP 1 blocking on enhancement of cell proliferation activity by rh174 in NHOst. NHOst were seeded at a density of $1 \times 10^{3}$ cells/well in a 96-well plate, and were cultured in OGM with $10 \%$ FBS until $60 \%$ confluence. Cells were treated with $100 \mathrm{ng} / \mathrm{ml} \mathrm{rh174}$ in the presence or absence of $20 \mu \mathrm{g} / \mathrm{ml} \mathrm{rabbit} \mathrm{anti-}$ LAMP 1 antibody in serum-free OGM. Cell proliferation activity was analyzed using a Cell Proliferation ELISA BrdU kit. ${ }^{*} P<0.01, n=3$.

\section{Discussion}

The phenotype of NHOst was characterized based on the expression levels of alkaline phosphatase (ALP), collagen type 1 collagen, osteocalcin (OC) and CD44, and the formation of mineralization nodules [17]. In the present study, the proliferation of NHOst cells was enhanced significantly by treatment with rh174, as compared to untreated controls.

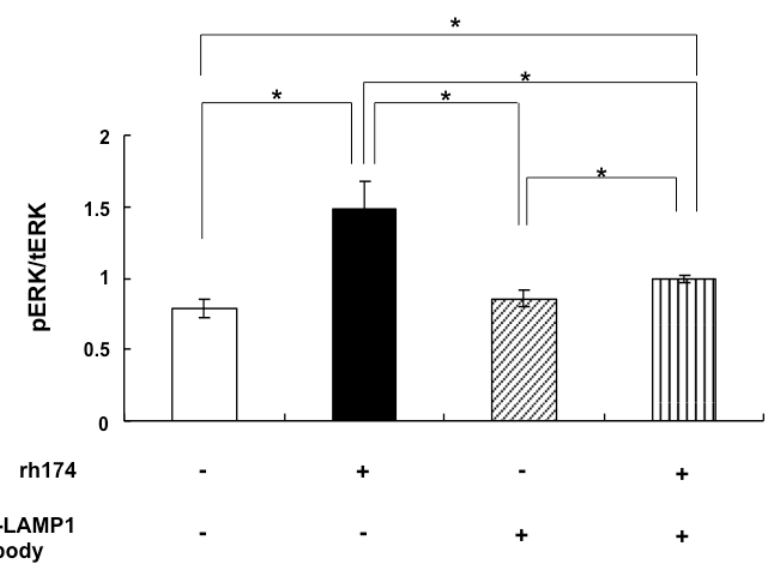

Figure 3. Activation of ERK signaling pathway by rh174/LAMP 1 interaction in NHOst (ELISA). NHOst were seeded at a density of $2 \times$ $10^{4}$ cells/well in a 96-well plate, and were cultured in $\alpha-M E M$ with $10 \% \mathrm{FBS}$ until $60 \%$ confluence. Cells were treated with $100 \mathrm{ng} / \mathrm{ml}$ rh174 in the presence or absence of $20 \mu \mathrm{g} / \mathrm{ml}$ rabbit anti-LAMP 1 antibody in serum-free OGM. ERK activity was measured at $30 \mathrm{~min}$ after treatment with rh174 using a CASE kit. The ratio of $p E R K$ to tERK was determined. $* P<0.01, n=3$.

In both in vitro/vivo studies, the effectiveness of EMDOGAIN for periodontal regeneration, including the formation of new cementum, bone, and dentin has been reported [17-21]. It has also been demonstrated that EMDOGAIN enhances the 
proliferation of various types of cells, such as immortalized murine cementoblasts (OCCM-30), pre-osteoblasts from mice OC-Tag (OCT-1) cells, and pre-osteoblasts from mouse calvaria cells (MC3T3-E1) [22]. In addition, it has been reported that EMDOGAIN stimulates proliferation of human gingival fibroblasts via the ERK signaling pathway [23]. However, it remains unclear whether the effects of EMDOGAIN are due to amelogenins, although approximately $90 \%$ of enamel matrix proteins are amelogenins, and the remaining $10 \%$ comprise non-amelogenin enamel matrix proteins and growth factors [24-26].

In addition, various isoforms and fragments of amelogenin in the enamel matrix may exert different functions; therefore, recombinant proteins have been used to examine the direct effects of amelogenins. For example, recent studies demonstrated that amelogenins enhance the proliferation of several cell types such as human periodontal ligament fibroblasts (PDLF) and gingival fibroblasts (GF). The proliferation activity of PDLF and GF was promoted by treatment with full-length porcine amelogenin. 27 Similarly, it has been reported that recombinant full-length porcine amelogenin (P172) induced a significant and dose-dependent increase in murine PDLF proliferation [28]. In addition, the proliferation of mouse PDL cells was enhanced by recombinant full-length murine amelogenin ( $\mathrm{rp}(\mathrm{H}) \mathrm{M} 180),[26]$ which is similar to the finding in this study that rh174 enhances the proliferation of NHOst cells.
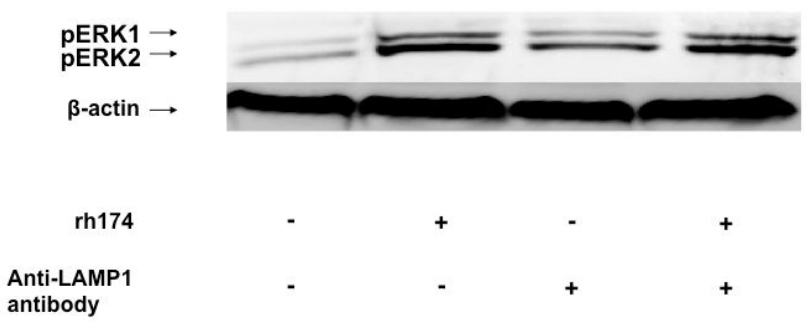

Figure 4. Activation of ERK signaling pathway by rh174/LAMP 1 interaction in NHOst (Western blot analysis). Western blot analysis revealed similar results for enhanced phosphorylated ERK1/2 signaling after addition of rh174. In addition, western blot analysis showed reduced phosphorylated ERK1/2 signaling after blocking of LAMP 1 antibody. Lower bands show the abundance of total ERK and $\beta$-actin as a loading control $(n=3)$.

LAMP 1 was originally identified as a major protein component of the lysosomal membrane [12]. It was identified as a cell surface receptor for a small isoform of amelogenin, [A-4]/M59 (leucine-rich amelogenin peptide; LRAP) in mesenchymal-derived mouse fetal myoblasts [14]. In addition, it was reported that several fragments derived from $\operatorname{rp}(\mathrm{H}) \mathrm{M} 180$ bind to LAMP 1 [29]. A recent study revealed that LAMP 1 serves as a cell surface binding site for amelogenins on mouse dental follicle cells and mouse cementoblasts [30].

It was recently reported that rh174 increased the proliferation of human mesenchymal stem cells (MSCs) by interaction with
LAMP 1 through the MAPK-ERK signaling pathway, indicating the possibility of MSC application to tissue regeneration in the orofacial region [31]. Similarly, in the present study, proliferation of NHOst was enhanced significantly by treatment with rh174, as compared to untreated controls, but was inhibited significantly by the addition of antiLAMP 1 blocking antibody. Furthermore, pERK1/2 expression in NHOst was significantly up-regulated by treatment with rh174, and was inhibited in the presence of anti-LAMP 1 blocking antibody. These results suggest that rh174 interacts with LAMP 1, and that rh174/LAMP 1 interaction activates the ERK1/2 signaling pathway, leading to the enhancement of cell proliferation activity in NHOst cells.

In a previous study, it has been reported that rh174 significantly enhances the proliferation of cultured human cementoblast lineage cells through cluster of differentiation (CD) 63 receptor-mediated activation of the ERK1/2 signaling pathway [32-36]. In this study, the proliferation activity of NHOst was enhanced significantly by treatment with rh174 and anti-LAMP1 antibody as compared to the non-treated control group. Alternatively, the ratio of pERK to tERK in NHOst became significantly larger by treatment with rh174 and anti-LAMP1 antibody, as compared to untreated controls. In addition, western blot analysis revealed similar results for enhanced phosphorylated ERK1/2 signaling after addition of rh174 and anti-LAMP1 antibody. It is assumed that amelogenins affect the metabolism of osteoblasts through both CD63 and LAMP1-mediated mechanisms. In addition, recent study has been demonstrated that amelogenin promotes the differentiation of odontoblast-like cells via the ERK1/2 and $p$ 38 MARK pathways [37]. Our previous study showed that rh174 and C-terminal amelogenin increased proliferation of human cementblasts through MAPK-ERK signaling pathway [38]. A recent in vitro study suggested that bone marrow MSC proliferation was increased in the presence of C-terminal of amelogenin and inhibited by anti-LAMP1 antibody or U0126. Increased phosphorylated ERK1/2 was observed in the presence of C-terminal of amelogenin, and decreased phosphorylated ERK1/2 was seen in the presence of antiLAMP1 antibody or U0126 [39]. Recently it has been demonstrated that human recombinant amelogenin remarkably enhanced LAMP-1 staining in mouse cementblasts [40]. In addition, it has been revealed that human recombinant amelogenin enhances the mineralization accompanied by the upregulation of bone markers (BSP and OCN) in mouse cementblasts [40]. From these studies may be valuable for future periodontal or bone regenerative medicine. Furthermore, comprehensive knowledge of these pathways is important for optimization of future amelogenin tissue engineering strategies.

In conclusion, it was shown that rh174 significantly enhances the proliferation of cultured NHOst via LAMP 1-mediated activation of the ERK1/2 signaling pathway, suggesting a possible application of amelogenin in cell proliferation and periodontal tissue engineering. 


\section{Acknowledgement}

We are grateful to Drs. Pamela DenBesten and $\mathrm{Wu} \mathrm{Li}$ of the Department of Orofacial Sciences, University of California, San Francisco, for kindly providing valuable technical support, advice, vector and antibody for rh174. This work was carried out at the Research Center for Molecular Medicine, Hiroshima University. This work was supported by JSPS KAKENHI Grant Number 16K11790, 15H06436, 23792428, 25893147, $15 \mathrm{~K} 20593,17 \mathrm{~K} 17328$ and $17 \mathrm{~K} 17330$.

\section{References}

1. Venezia E, Goldstein M, Boyan BD, Schwartz Z. The use of enamel matrix derivative in the treatment of periodontal defect: a literature review and meta-analysis. Crit Rev Oral Biol Med 2004; 15: 382-402.

2. Hammarström L. Enamel matrix, cementum development and regeneration. J Clin Periodontol 1997; 24: 658-668.

3. Heden G, Wennstrom J, Lindhe J. Periodontal tissue alterations following Emdogain treatment of periodontal sites with angular bone defects: a series of case reports. J Clin Periodontol 1999; 26: 855-860.

4. Sculean A, Reich E, Chiantella GC, Brecx M. Treatment of intrabony periodontal defects with an enamel matrix protein derivative (Emdogain): A report of 32 cases. Int $\mathrm{J}$ Periodontics Restorative Dent 1999; 19: 157-163.

5. Mellonig JT. Enamel matrix derivative for periodontal reconstructive surgery: technique and clinical and histologic case report. Int J Periodontics Restorative Dent 1999; 19: 8-19.

6. Tonetti M, Lang N, Cortellini P. Enamel matrix proteins in the regenerative therapy of deep intrabony defects. J Clin Periodontol 2002; 29: 317-325.

7. Sasaki S, Shimokawa H. The amelogenin gene. Int J Dev Biol 1995; 39: 127-133.

8. Snead ML. Amelogenin protein exhibits a modular design: implications for form and function. Connect Tissue Res 2003; 44: 47-51.

9. Ryu $\mathrm{OH}, \mathrm{Hu} \mathrm{CC}$, Simmer JP. Biochemical characterization of recombinant mouse amelogenins: protein quantitation, proton absorption, and relative affinity for enamel crystals. Connect Tissue Res 1998; 38: 207-214.

10. Gibson CW, Yuan ZA, Hall B, Longenecker G. Amelogenin-deficient mice display an amelogenesis imperfecta phenotype. J Biol Chem 2001; 276: 31871-31875.

11. Hatakeyama J, Sreenath T, Hatakeyama Y. he receptor activator of nuclear factor-kappa B ligand-mediated osteoclastogenic pathway is elevated in amelogenin-null mice. J Biol Chem 2003; 278: 35743-35748.

12. Cook NR, Row PE, Davidson HW. Lysosome associated membrane protein 1 (LAMP 1) traffics directly from the TGN to early endosomes. Traffic 2004; 5: 685-699.

13. Kannan K, Stewart RM, Bounds W. Lysosome-associated membrane proteins h-LAMP1 (CD107a) and h-LAMP2
(CD107b) are activation-dependent cell surface glycoproteins in human peripheral blood mononuclear cells which mediate cell adhesion to vascular endothelium. Cell Immunol 1996; 171: 10-19.

14. Tompkins K, George A, Veis A. Characterization of a mouse amelogenin [A-4]/M59 cell surface receptor. Bone 2006; 38: 172-180.

15. DenBesten PK, Yan Y, Featherstone JD, Hilton JF, Smith $\mathrm{CE}, \mathrm{Li} \mathrm{W}$. Effects of fluoride on rat dental enamel matrix proteinases, Arch Oral Biol 2002; 47: 763-770.

16. Li W, Gao C, Yan Y, DenBesten PK. X-linked amelogenesis imperfecta may result from decreased formation of tyrosine rich amelogenin peptide (TRAP). Arch Oral Biol 2003; 48: 177-183.

17. Thommesen L, Stunes AK, Monjo M. Expression and Regulation of Resistin in Osteoblasts and Osteoclasts Indicate a Role in Bone Metabolism. J Cell Biochem 2006; 99: 824-834.

18. Venezia E, Goldstein M, Boyan BD, Schwartz Z. The use of enamel matrix derivative in the treatment of periodontal defect: a literature review and meta-analysis. Crit Rev Oral Biol Med 2004; 15: 382-402.

19. Heden G, Wennstrom J, Lindhe J. Periodontal tissue alterations following Emdogain treatment of periodontal sites with angular bone defects: a series of case reports. J Clin Periodontol 1999; 26: 855-860.

20. Sculean A, Reich E, Chiantella GC, Brecx M. Treatment of intrabony periodontal defects with an enamel matrix protein derivative (Emdogain): a report of 32 cases. Int J Periodontics Restorative Dent 1999; 19: 157-163.

21. Tonetti M, Lang N, Cortellini P Suvan JE. Enamel matrix proteins in the regenerative therapy of deep intrabony defects. J Clin Periodontol 2002; 29: 317-325.

22. Tokiyasu Y, Takata T, Saygin E, Somerman M. Enamel factors regulate expression of genes associated with cementoblasts. J Periodontol 2000; 71: 1829-1839.

23. Zeldich E, Koren R, Nemcovsky C, Weinreb M. Enamel matrix derivative stimulates human gingival fibroblast proliferation via ERK. J Dent Res 2007; 86: 41-46.

24. Cerny R, Slaby I, Hammarström L, Wurtz T. A novel gene expressed in rat ameloblasts codes for proteins with cell binding domains. J Bone Miner Res 1996; 11: 883-891.

25. Kawase T, Okuda K, Momose M, Kato Y, Yoshie H, Burns DM. Enamel matrix derivative (EMDOGAIN) rapidly stimulates phosphorylation of the MAP kinase family and nuclear accumulation of smad 2 in both oral epithelial and fibroblastic human cells. J Periodontal Res 2001; 36: 367-376.

26. Zeichner-David M, Chen LS, Hsu Z, Reyna J, Caton J, Bringas M. Amelogenin and ameloblastin show growthfactor like activity in periodontal ligament cells. Eur J Oral Sci 2006; 114: 244-256.

27. Li X, Shu R, Liu D, Jiang S. Different effects of 25-kDa amelogenin on the proliferation, attachment and migration of various periodontal cells. Biochem Biophys Res Commun 2010; 394: 581-586. 
28. Hatakeyama J, Philp D, Hatakeyama Y. Amelogeninmediated regulation of osteoclastogenesis, and periodontal cell proliferation and migration. J Dent Res 2006; 85: 144-149.

29. Zou Y, Wang H, Shapiro JL. Determination of protein regions responsible for interactions of amelogenin with CD63 and LAMP1. Biochem J 2007; 408: 347-354.

30. Zhang H, Tompkins K, Garrigues J, Snead ML, Gibson $\mathrm{CW}$, Somerman MJ. Full length amelogenin binds to cell surface LAMP-1 on tooth root/periodontium associated cells. Arch Oral Biol 2010; 55: 417-425.

31. Huang YC, Tanimoto K, Tanne Y, Kamiya T. Effects of human full-length amelogenin on the proliferation of human mesenchymal stem cells derived from bone marrow. Cell Tissue Res 2010; 342: 205-212.

32. Xu L, Harada H, Yokohama T, Matsumoto S, Tanaka J, Taniguchi A. Reuptake of extracellular amelogenin by dental epithelial cells results in increased levels of amelogenin mRNA through enhanced mRNA stabilization. J Biol Chem 2006; 281: 2257-2262.

33. Wang H, Tannukit S, Zhu D, Snead ML, Paine ML. Enamel matrix protein interactions. J Bone Miner Res 2005; 20: 1032-1040.

34. Stipp CS, Kolesnikova TV, Hemler ME. Functional domains intetraspanin proteins. Trends Biochem Sci 2003; 28: 106-112.

35. Yunta M, Lazo PA. Tetraspanin proteins as organisers of membrane microdomains and signalling complexes. Cell Signal 2003; 15: 559-564.
36. Kunimatsu R, Tanimoto K, Tanne Y. Amelogenin enhances the proliferation of cementoblast lineage cells. J Periodontol 2011; 82: 1632-1638.

37. Yao N, Li S, Jiang Y, Qiu S, Tan Y. Amelogenin promotes odontoblast-like MDPC-23 cell differentiation via activation of ERK1/2 and p38 MAPK. Mol Cell Biochem 2011; 35: 91-97.

38. Yoshimi Y, Kunimatsu R, Hirose N. Effects of C-terminal amelogenin peptide on proliferation of human cementoblast lineage cells. J Periodontol 2016; 87: 820-827.

39. Kunimatsu R, Awada T, Yoshimi Y. The C-terminus of the amelogenin peptide influences the proliferation of human bone marrow mesenchymal stem cells. J Periodontol 2018; 89: 496-505.

40. Hakki SS, Bozkurt SB, Türkay E, Dard M, Purali N, Götz W. Recombinant amelogenin regulates the bioactivity of mouse cementoblasts in vitro. Int J Oral Sci 2018; 9: 15.

\section{*Correspondence to}

Ryo Kunimatsu

Department of Orthodontics and Craniofacial Developmental Biology

Hiroshima University Graduate School of Biomedical Sciences Japan 